\title{
Cues, Values and Conflict: Reassessing Evolution Wars Media Persuasion
}

\section{THOMAS AECHTNER}

Faculty of Humanities and Social Sciences

University of Queensland

t.aechtner@uq.edu.au

ORCID: 0000-0002-0296-9339

\begin{abstract}
It has been posited that persuasive cues impart Evolution Wars communications with persuasive force extending beyond the merits of their communicated arguments. Additionally, it has been observed that the array of cues displayed throughout proevolutionist materials is exceeded in both the number and nuance of Darwin-skeptic persuasion techniques. This study reassesses these findings by exploring how persuasive cues in the Evolution Wars are being articulated with reference to the Cultural Cognition Thesis and Moral Foundations Theory. Observations of Institute for Creation Research,Answers in Genesis, and the Center for Science and Culture media are reevaluated. These findings are juxtaposed with data pertaining to Richard Dawkins Foundation for Reason and Science, National Center for Science Education, and BioLogos Foundation broadcasts. The outcomes reveal how values claims and morally charged language are concentrated within the works of antievolutionists and New Atheist media makers, who collectively promote some manner of religion-science conflict.
\end{abstract}

Keywords: Antievolutionism; Intelligent Design; Cultural Cognition; Moral Foundations; New Atheism; Media Persuasion. 


\section{Introduction}

In 1949, when the propaganda campaigns of WWII were still fresh in people's minds, Dorwin Cartwright reasoned, "It is conceivable that one persuasive person could, through the use of mass media, bend the world's population to his will" $(1949,253)$. Though such hypodermic-syringe model claims are no longer accepted, it is evident that mass communications can influence audiences in rather oblique ways. This includes media effects resulting from the tendency of individuals to rely upon cognitive heuristics, or cues, in response to persuasive messages. Notably, it has been posited that these cues are at work in the Evolution Wars, and that they impart both Darwin-skeptic and proevolutionist communications with persuasive force extending beyond the merits of their communicated arguments (Aechtner 2014, 2016a). In cataloging such elements within antievolutionist and counter-creationist media, it has been revealed that the number and assortment of suasion factors displayed in Darwin-skeptic communications surpasses those exhibited throughout proevolutionist materials. Nevertheless, there remain additional persuasion dynamics yet to consider. These dimensions relate to how culturally cognitive prompts are employed in tandem with persuasive cues, as well as the ways in which messages are being morally framed for inducement effects. For that reason, the present study extends analyses of Evolution Wars communications by exploring how persuasive cues are being conveyed in relation to both the Cultural Cognition Thesis and Moral Foundations Theory. This reveals how values claims and morally charged language are concentrated within the works of antievolutionists and New Atheist media makers, who collectively promote some manner of religion-science conflict.

\section{Evolution Wars Media Persuasion}

The Evolution Wars represent ongoing debates associated with religiously motivated antievolutionism and scientific theories of origins. A hallmark of these so-called wars has been the use of every available mass media channel by Darwin-skeptics to disseminate antievolutionist messages worldwide, leading 
to a corresponding rise in proevolutionist endeavors. In previous studies, I implemented a content analysis of media produced by leading Darwin-skeptic and proevolutionist groups, gauging the occurrence rates of persuasive cues associated with the Elaboration Likelihood Model of persuasion (Aechtner 2014, 2016a). The Darwin-skeptic cohort included materials broadcasted by the Institute for Creation Research (ICR), Answers in Genesis (AiG), and the Discovery Institute's Center for Science and Culture (CSC). The first two represent the largest and most influential Young Earth Creationist institutions, while the latter is the world's leading Intelligent Design organization. The proevolutionist media incorporated materials associated with the Richard Dawkins Foundation for Reason and Science (RDFRS), the National Center for Science Education (NCSE), and the BioLogos Foundation (BLF). The RDFRS embodies strident proevolutionist, antireligious ideologies maintained by the 'New Atheists.' The NCSE, on the other hand, is a religiously neutral organization dedicated to educating the public on scientific matters, while BioLogos is the world's chief Christian proevolutionist advocacy group.

The Elaboration Likelihood Model of persuasion, developed by Richard E. Petty and John T. Cacioppo (1986), was employed as the conceptual framework for analyzing Evolution Wars mass media. This model is one of the most widely accepted and empirically substantiated descriptions of persuasion. In short, it suggests that there are two major avenues of persuasion that result from exposure to communications: the central and peripheral routes (Petty and Cacioppo 1984, 70). The first consists of attitude change occurring via an individual's diligent scrutiny of a persuasive message. This route involves 'high elaboration,' which requires both the motivation and the ability to carefully examine a message's arguments. The second route, on the other hand, ensues when there is a lack of motivation or ability to thoroughly process a persuasive message's contentions. In such 'low elaboration' circumstances individuals are likely to rely upon various mental shortcuts, or peripheral cues, to help formulate opinions and behaviors (Anastasio, Rose, and Chapman 1999, 154). Such cues are used to make decisions in part because people often seek to exert the least amount of effort possible for the analysis of pervasive communications (Stiff and Mongeau 2003, 230). Due to the explanatory success 
of the Elaboration Likelihood Model, an inventory of peripheral cues isolated throughout persuasion research was employed to analyze text-based media disseminated by Darwin-skeptic and proevolutionist groups. This coding list included the following catalogue of persuasive message variables:

1. Arousal of Fear

2. Asking Questions

3. The Contrast Principle and Negativity Effect (CPNE)

4. Disrupt-then-Reframe

5. Message Repetition

6. Number of Message Arguments

7. Rule of Reciprocity

8. Scarcity Principle

9. Self-Referencing

10. Social Consensus

11. Source Cues

12. Statistics and Technical Jargon (STJ)

13. Two-Sided Persuasion

The coding analysis involved isolating how frequently these thirteen persuasive attributes appeared in Evolution Wars media produced from 2009 to 2011. Specifically, persuasive message variables exhibiting $\geqslant 0.400$ occurrences per 1000 words were identified, and descriptions were provided regarding the idiosyncratic ways each is expressed. The codes featuring notable incident rates are catalogued in Tables 1 and 2, which also rank each variable according to their overall frequency values in either Darwin-skeptic or proevolutionist media. Though these outcomes are considered in detail elsewhere, it should be noted that proevolutionist media offer a smaller assortment of persuasive variables, often delivered at lower rates of recurrence than Darwin-skeptic communications. Yet, while the assortment of suasion factors displayed in counter-creationist materials is surpassed by both the number and nuance of Darwin-skeptic cues, there are additional persuasion factors to take into account. These relate to a growing body of decision-making research associated with theories of cultural cognition and the influences of moral intuitions. 
Table 1. Message Variables Exhibiting $\geqslant 0.400$ Incident Rates per 1000 Words in Darwin-Skeptic Media

\begin{tabular}{|c|c|c|c|c|c|c|}
\hline \multirow{2}{*}{$\begin{array}{l}\text { Message } \\
\text { Variable }\end{array}$} & \multicolumn{2}{|c|}{$\begin{array}{l}\text { Institute for } \\
\text { Creation Research }\end{array}$} & \multicolumn{2}{|c|}{ Answers in Genesis } & \multicolumn{2}{|c|}{$\begin{array}{l}\text { Center for Science } \\
\text { and Culture }\end{array}$} \\
\hline & $\begin{array}{c}\text { Incidents } \\
\text { per } 1000 \\
\text { Words }\end{array}$ & Rank & $\begin{array}{c}\text { Incidents } \\
\text { per } 1000 \\
\text { Words }\end{array}$ & Rank & $\begin{array}{c}\text { Incidents } \\
\text { per } 1000 \\
\text { Words }\end{array}$ & Rank \\
\hline $\begin{array}{l}\text { Sources } \\
\text { Cues }\end{array}$ & 3.408 & 1 & 3.562 & 1 & 1.038 & 3 \\
\hline $\begin{array}{l}\text { Asking } \\
\text { Questions }\end{array}$ & 1.958 & 2 & 2.866 & 2 & 2.030 & 2 \\
\hline CPNE & 1.902 & 3 & 1.431 & 4 & 2.770 & 1 \\
\hline STJ & 0.790 & 5 & 1.188 & 5 & 0.592 & 5 \\
\hline $\begin{array}{l}\text { Social } \\
\text { Consensus }\end{array}$ & 1.047 & 4 & 0.481 & 3 & -- & -- \\
\hline $\begin{array}{l}\text { Scarcity } \\
\text { Principle }\end{array}$ & -- & -- & -- & -- & 0.882 & 4 \\
\hline $\begin{array}{l}\text { Message } \\
\text { Repetition }\end{array}$ & -- & -- & 0.407 & 6 & -- & -- \\
\hline
\end{tabular}

Table 2. Message Variables Exhibiting $\geqslant 0.400$ Incident Rates per 1000 Words in Proevolutionist Media

\begin{tabular}{|c|c|c|c|c|c|c|}
\hline \multirow{2}{*}{$\begin{array}{l}\text { Message } \\
\text { Variable }\end{array}$} & \multicolumn{2}{|c|}{$\begin{array}{l}\text { Richard Dawkins } \\
\text { Foundation for } \\
\text { Reason and Science }\end{array}$} & \multicolumn{2}{|c|}{$\begin{array}{l}\text { National Center for } \\
\text { Science Education }\end{array}$} & \multicolumn{2}{|c|}{$\begin{array}{l}\text { BioLogos } \\
\text { Foundation }\end{array}$} \\
\hline & $\begin{array}{l}\text { Incidents } \\
\text { per } 1000 \\
\text { Words }\end{array}$ & Rank & $\begin{array}{l}\text { Incidents } \\
\text { per } 1000 \\
\text { Words }\end{array}$ & Rank & $\begin{array}{l}\text { Incidents } \\
\text { per } 1000 \\
\text { Words }\end{array}$ & Rank \\
\hline $\begin{array}{l}\text { Asking } \\
\text { Questions }\end{array}$ & 2.914 & 1 & 0.939 & 3 & 1.503 & 1 \\
\hline $\begin{array}{l}\text { Sources } \\
\text { Cues }\end{array}$ & -- & -- & 2.273 & 1 & 1.391 & 2 \\
\hline CPNE & 2.192 & 2 & 1.108 & 2 & 0.403 & 4 \\
\hline STJ & -- & -- & 0.746 & 5 & 0.645 & 3 \\
\hline $\begin{array}{l}\text { Social } \\
\text { Consensus }\end{array}$ & -- & -- & 0.758 & 4 & -- & -- \\
\hline
\end{tabular}




\section{Cultural Cognition and Moral Foundation Theory}

The Cultural Cognition Thesis, developed in large part by Dan Kahan, helps to delineate how ordinary citizens assess risk and make judgements in relation to such topics as climate change, gun control, and vaccinations (Kahan et al. 2015). It has been found that people are disposed to endorse whichever position on these issues best affirms the core values that define their identities, and what they already assume is true, rather than merely objective facts. This tendency has been described as identity-protective cognition, and through it people favor ideas supporting the cultural worldviews maintained within the groups that they self-identify (Kahan and Braman $2008,5)$. As a result, people selectively attend to facts in ways that validate their cultural worldviews, choosing to stick with notions that are compatible with their current beliefs, while being highly suspicious of data infringing upon the cultural values associated with their group ties.

Importantly, identity-protective reasoning and persuasion frameworks involving cues, or heuristics, are not mutually exclusive (Kahan et al. 2010, 503). The Cultural Cognition Thesis integrates both schemas, such that heuristic mechanisms are envisaged as working in concert with the influence of cultural values and social group membership. For instance, cultural cognition directly affects perceptions of credibility in the sense that "individuals more readily impute expert knowledge and trustworthiness to information sources whom they perceive as sharing their worldviews and deny the same to those whose worldviews they perceive as different from theirs" (Kahan, Jenkins-Smith, and Braman 2011, 3-4). Consequently, in relation to the Elaboration Likelihood Model, a messenger's credibility would conceivably be effective as a cue if the communicator with whom credibility is affixed maintains values associated with message recipients' cultural outlooks (Kahan 2012, 749-750). Accordingly, persuasive cues such as a source's ostensible credibility operate in conjunction with cultural cognition, because people are likely to ascribe import to expertise, and recollect the professed credibility of a source, when messengers demonstrate congenial cultural values. 
In considering the significance of cultural cognition, it should also be noted that core in-group values and cultural commitments can be moral convictions that socially bind people together. Taking this into account, it is worth considering the main premises of the Moral Foundations Theory conceived by Jonathan Haidt and Jesse Graham (2007). The theory addresses how moral intuitions frequently guide decision-making by identifying several key psychological foundations of morality, which seem to produce quick and automatic emotional reactions that can influence how people make decisions. Thought to be innate, these central foundations are said to operate as 'gut level' responses that provisionally included the following primary moral axes: care/harm, fairness/reciprocity, in-group/loyalty, authority/respect, and purity/sanctity (104-106). Care/harm features concern for the wellbeing of others and the prevention of harm, including upholding such virtues as compassion and kindness. The fairness/reciprocity dimension relates to treating people fairly, maintaining justice, and defending the rights of citizens as well as people's personal autonomy. The in-group/loyalty moral facet involves dedication to group membership contra distrust for non-group individuals, and self-sacrifice for one's community, which are together integrated into patriotic impulses. Authority/respect includes reflexive respect for hierarchy, obedience to legitimate authority, duty, admiration for those in power, and the veneration of traditions. Purity/sanctity exemplifies the psychology of disgust and prevention of contamination, leading to the regulation of bodily processes and biological pollutant avoidance. This intuition is linked to concepts of religious sacredness, such that some ideas or objects are treated as having inviolable value. Since formulating these categories other potential axes have been considered, though most research has been delimited to the five domains described here.

While the theory is not without detractors, it is useful in directing attention to the influence of emotion-driven moral sensitivities. Attitude formation associated with political sentiment and scientific theories seem at least moderately related to considerations of moral values, and the precedence of certain moral foundations. For this reason, moral appeals can act as a type of persuasive heuristic in communications when the moral 
foundations petitioned within a message correspond to the moral profiles of targeted audiences. With regards to the Elaboration Likelihood Model, it has also been found that communications exhibiting characteristics matching an audience's attitudes or traits result in increased cognitive elaboration and central route processing. Such messages can lead to enhanced persuasiveness for recipients, who also tend to think more positively about the message's source (Wheeler, Petty, and Bizer 2005). In accordance with these findings, communications conveying moral values matching up with the emotion-heavy moral foundations expressed by specific audiences will also likely be more persuasive (Wolsko, Ariceaga, and Seiden 2016, Day et al. 2014).

With these considerations in mind, this study now returns to persuasive cues exhibited in Evolution Wars media. The goal will be to evaluate the ways in which the most prevalent cues are expressed in relation to both cultural cognition and moral foundations. To that end, analysis commences with an examination of the message variables described as Source Cues and Message Repetition.

\section{Source Cues}

\subsection{Messenger Credibility}

In situations of low elaboration likelihood the alleged expertise and perceived credibility of communicators has been demonstrated to act as a significant peripheral cue (Petty and Cacioppo 1986, 142-143). For instance, a message's persuasive arguments tend to be accepted far more readily when a communicator is described as possessing prestigious academic credentials. Credibility can also be increased through certain attire, such as a police officer's uniform or a lab coat, and even the presence of specific symbols and scientific instruments can generate perceptions of academic authority and credibility (Karmarkar and Tormala 2010, Priester and Petty 2003). Messenger Credibility cases are identified as displays of academic qualifications and expertise in persuasion attempts, along with the inclusion of symbols and objects that represent authority and communicator trustworthiness. 


\subsection{Source Attraction}

A source's apparent likeability and physical attractiveness can also function as a persuasive cue (Petty and Cacioppo 1986, 144-146). Professional athletes and Hollywood celebrities, for example, are generally perceived to be highly-likeable, attractive individuals, and their mere presence in communications readily affects peripheral persuasion. In addition to likeability fueled by celebrity status and attractiveness, it is evident that individuals also tend to be much more amenable to people who give them compliments, or who express even the most incidental similarities to themselves (Burger et al. 2004). The expression of shared values also acts in this way, as does the use of common cultural symbols, such as a country's flag. The utilization of celebrity status, audience flattery, important religious/cultural symbols, as well as a focus on shared values and communicator-audience commonalities, are all considered cases of Source Attraction.

In concert with both Source Attraction and Messenger Credibility, the persuasive cue described as Message Repetition appears at significant rates explicitly in Answers in Genesis media. These cases of repetition in AiG's Answers magazine frequently intersect with locutions of Source Cues. On that note, it is necessary to discuss this persuasion technique before moving forward.

\section{Message Repetition}

During WWII, Floyd H. Allport and Milton Lepkin (1945) conducted a study on why false wartime rumors persisted in the United States. They found that the single best predictor of belief in a rumor was whether hearers had heard the rumor before, usually on several occasions. Mere repetition seemed to be central to the acceptance and subsequent spreading of misinformation. Nevertheless, the persuasive mechanisms of repetition appear to be quite complex. Petty and Cacioppo $(1986,69)$ found that repetition increases message recall, and can actually stimulate motivation to process communicated arguments. However, excessive repetition can cause "tedium or 
reactance and bias recipients' message processing-in particular, to cause them to counterargue even strong arguments and proattitudinal positions" (131). Accordingly, cosmetic variation, which includes simply changing such features as background pictures in advertisements, or the slight rewording of a reiterated message, can enhance product recall and peripheral persuasion in low elaboration contexts (Shumann, Petty, and Clemons 1990). In a previous study, cases of Message Repetition were distinguished as the recurrence of a message at least three times within the same article, which included identifying cosmetic variation in Evolution Wars media (Aechtner 2014, 194).

\section{Reexamining Source Cues and Repetition}

Source Cues represent one of the most readily-occurring persuasive constituents in Darwin-skeptic mass media, while also being an important feature of National Center for Science Education and BioLogos Foundation proevolutionist materials. These findings reinforce the significance of this message variable in terms of the relative number of times it is expressed across Evolution Wars communications, aside from New Atheist media. Nevertheless, while Source Cues are a hallmark persuasive attribute of NCSE and BioLogos materials, it is evident that Young Earth Creationist articles are still far more likely to include references to Messenger Credibility and Source Attraction than either proevolutionist or Intelligent Design broadcasts. There are also further vicissitudes to credibility and attraction claims that ought to be considered, which may overlie the occurrence rates of persuasive cues with another level of media stimuli. For instance, there are degrees to which Darwin-skeptic and proevolutionist materials include, or are absent of, references to specific culturally cognitive premises and morally foundational axes.

National Center for Science Education articles contain a higher proportion of Source Cues than any other observed persuasion element expressed in the organization's media collection. These appeals are articulated almost exclusively as brief mentions of the academic expertise maintained by those 
who espouse evolutionary science, as well as the scholarly credentials of proevolutionists. Importantly, however, NCSE expressions of Source Cues exhibit hardly any references to shared values, cultural commitments, or language suggestive of moral foundations. Meanwhile, BioLogos messages only occasionally reference the sacred authority of scripture and Christian values while invoking scientific credibility. By contrast, these observations differ considerably from what is found in Darwin-skeptic media. Case in point, Institute for Creation Research members not only maintain that creationism is the basis of paradigm-altering scientific research that brandishes support from many highly credentialed scientists, scientists of the past, and an abundance of empirical data. ICR media also persistently refers to creationism's cause as being divinely sanctioned, while claiming that the institute's mission ensues directly from valuing the Bible as Holy Scripture. In fact, according to ICR communications, Jesus Christ himself interpreted the Bible in the same fashion as Young Earth Creationists, while the biblical authors employed an identical hermeneutic to the one allied with Young Earth Creationism (Johnson 2010, Snelling 2009, Morris 2011 [1995]). In addressing Christian audiences, Acts\&Facts spokespersons also stress that ICR's members maintain commonly shared Evangelical Christian values associated with the importance of Jesus Christ and his atonement, as well as doctrines regarding humankind's divine image and intrinsic worth. As a matter of fact, creationism is styled as conforming to God's very nature (Snelling 2009, Forlow 2011). Additionally, U.S. publics are told of how the Institute for Creation Research upholds such American cultural values of 'freedom' and 'liberty' (Ford 2010a).

Consequently, while Acts\&Facts articles are saturated with Messenger Credibility claims of secular, scientific competencies, ICR media goes beyond proevolutionist communications in validating Evangelical Christian worldviews and affirming key socio-religious values maintained by targeted American audiences. With reference to this articulation of Source Cues, we can also return to the Moral Foundations Theory and the authority/respect intuition. In taking this foundation into account, we may further reassess the persuasiveness of Acts\&Facts claims about ICR experiencing divine succor, 
and declarations that the institute is representative of authentic Christianity, deriving credibility from the sovereignty of God and the authority of scripture. For Christian audiences predisposed to respecting the Bible as the infallible Word of God, Institute for Creation Research expressions of Source Cues conceivably tap into another level of persuasion beyond mere claims of academic expertise. This dimension involves the influence of emotionally-driven moral sensitives affiliated with weighty sources of Christian authority.

The reflexive sway of the authority/respect moral foundation may also be at work via the enunciation of Source Cues within Answers in Genesis communications. Answers in Genesis writers use appeals to sacred authority to a greater degree than any other Evolution Wars organization (Aechtner 2014). Throughout such appeals, AiG's media makers insist that assenting to creationism equates to trusting in God himself, rather than error-prone and immoral human beings (Hodge 2011). Hence, the authority of the group's antievolutionism may be confirmed by academic credentials and scientific data, but ultimately it is endorsed by God's authoritative voice. Concurrently, Answer in Genesis broadcasts also cultivate in-group partisanship by actively designating Young Earth Creationism as the weltanschauung most congruous with Christian values and genuine Christian faith. All other worldviews maintained by both out-group Christians and non-Christians deny, at some level, the trustworthiness of God while rejecting such core Evangelical principles as reverence for scripture. Source Cues in Answers magazine recurrently delimit what is and apparently is not authentic Christianity, with Young Earth Creationism acting as the benchmark of ideal hermeneutics and religious faith. In this way, Answers in Genesis cases of Source Cues can be seen mustering the in-group/loyalty moral foundation. Source Cues in AiG materials thus fasten together religious and secular credibility claims with demarcations of Evangelical Christian in-group line items, and out-group disloyalty. The integrity of Young Earth Creationists and their hermeneutics are entwined with the credibility of God's eyewitness testimony, the religious authority of Jesus Christ, and the biblical authors. Accordingly, any rejection of Young Earth Creationism is 
likened to a denunciation of scripture itself, its authors, and the Messiah; stationing both Christian and non-Christian deniers in a camp separated from true in-group Christian devotees (Landis 2011).

Assertions linking creationism's credibility to several Christian cultural commitments, including faith in God and esteem for the Bible, could further assist in developing cultural credibility with audiences who accept similar convictions. Other Christian cultural values are tenaciously referenced in AiG's expressions of Message Repetition, which frequently intersect through Source Cues in Answers magazine. This includes reiterating such shared Christian beliefs as the acceptance of humanity's Imago Dei, and the intrinsic value of all people (Bauchman 2009, Menton 2010). By the same token, the Center for Science and Culture's Intelligent Design-defending media also occasionally connects Messenger Credibility statements with the institute's concern for the image of God in humanity and the importance of human distinctiveness, which are values culturally consistent to those maintained by many theists (Egnor 2009a). As a result, it can be observed that even though CSC communications present fewer cases of Source Cues than either National Center for Science Education or BioLogos counter-creationist media, when they do so Intelligent Design broadcasts are disposed to mentioning culturally cognitive values. As a matter of fact, all Darwin-skeptic communications express Source Cues together with shared values and defining group commitments that may animate morally foundational axes, in ways that are not observable in proevolutionist materials. Nonetheless, while this may be true of Source Cues and Message Repetition, the circumstances are rather different when it comes to Asking Questions and New Atheist mass communications.

\section{Asking Questions}

In previous analyses this persuasive cue has been identified as the use of rhetorical queries, also known as eroteme, which involve asking a question without expecting an answer because the answer itself is strongly implied within the question itself (Aechtner 2014, 192, 2016a, 85). This variable can 
spark message processing in low elaboration likelihood contexts, particularly when audiences exhibit an initial lack of interest in a communication's claims (Petty and Cacioppo 1986, 198-203, Ahluwalia and Burnkrant 2004). Asking Questions also includes the rhetorical tools described as anacoenosis and hypophora. The first involves asking the opinion of message recipients in a manner that does not require an answer by inferring common interest, while the second technique comprises asking a question and then promptly answering it (Lanham 1991, 9-10, 71, 87).

\section{Asking Questions and Values Discourses}

Asking Questions boasts the second highest frequency rate of any message variable detected in antievolutionist media. It is also the most ubiquitous persuasion heuristic appearing in both RDFRS and BioLogos Foundation communications, while it is the third most common element identified in National Center for Science Education materials. Overall, Evolution Wars media from all sides of the fray are permeated with erotema, hypophora, and anacoenosis. Once again, however, variations in the ways that this persuasion device is conveyed with respect to culturally cognitive values discourse and moral framing reveal further insights into the communicative nuances of such broadcasts. To illustrate some of these distinctions, a reevaluation of Asking Questions cases in NCSE and BioLogos articles divulges how both group's media are unlikely to refer to cultural values or moral ideals when posing rhetorical questions. Darwin-skeptic and New Atheist utilizations of rhetoricals, on the other hand, trend in quite the opposite direction.

Throughout RDFRS media, rhetorical queries largely appear within denouncements of ideas or individuals that do not conform closely enough to New Atheist perspectives on religion and science. This entails iteratively questioning the rationality of religious believers, and why some individuals would insist that science and religion are not necessarily in direct and perennial conflict (Aechtner 2016a, 85-86). In this way, rhetorical questions fortify central New Atheist tenets, including the value of irreligious 
reason, and the inevitability of science-religion antagonism. Effectively, many instances of Asking Questions serve to convey fundamental atheist stances, which would also have cultural credibility for likeminded audiences. RDFRS rhetorical queries also provoke moral considerations, as New Atheist writers challenge the ethics of the Roman Catholic Church's response to sexual abuse crimes committed by clergy, while interrogating the origins of morality, and criticizing Islam for engendering terrorism (Dawkins 2010, Harris 2010a). What can be identified are series of value-laden, and worldview ratifying questions, which may also generate in-group/loyalty moral foundational responses (Coyne 2009, Harris 2009). In using rhetorical questions to castigate individuals and ideas that do not comport with New Atheist mores, RDFRS media establish what people and viewpoints belong to the rationally, and often ethically confused outgroup, versus the sensible and scientifically minded company of nonbelievers.

In-group/loyalty prompts are also embedded within Darwin-skeptic rhetoricals, including Institute for Creation Research erotema that repeatedly inquire how Christians could, in good conscience, accept both scripture and non-creationist assumptions. These rhetorical queries call into question whether individuals who do not fully adopt Young Earth Creationism can truly be deemed faithful Christians at all (Ford 2010b). Similar cases of Asking Questions in Answers in Genesis media likewise distinguish Christian creationist in-group confederates from non-Young Earth outsiders, while calling upon the devotion of audience members by asking whether they, as true believers, will trust God in the face of anti-biblical scientific threats (Ham 2011b, Mortenson 2010).

Such questions may further elicit authority/respect moral sentiments, as they rhetorically ask what source of truth is more authoritative: the certainty of the Bible or the findings of disputed science (Matthews 2010, Lawton 2010)? Darwin-skeptic communications also feature cases of Asking Questions which cast doubt upon the scientific validity of evolution, and the moral character of evolutionists (Upchurch 2011). These types of queries insinuate that, unlike in-group underdog scientists, proevolutionists are embellishing what little empirical evidence they have in order to deceitfully 
corroborate evolutionary theory. The Center for Science and Culture's use of rhetorical inquiries also does this, while putting special emphasis on conspiracist allegations involving self-seeking academics, bullying, and widespread censorship of Intelligent Design-supporting facts (Egnor 2009c, Smith 2011, Klinghoffer 2009a). In effect, these rhetoricals can be tagged as appeals to fairness/reciprocity intuitions. With its questions about why scientists are trying to impede academic freedom, censor data, and force an apparently untested science upon the masses, CSC's News and Views recurrently engage readers on the issue of fairmindedness and personal liberties. In this way, Intelligent Design media also refer to sociocultural values associated with notions of academic freedom and the right to independent thought. Suchlike discussions of fairness and suppression also frame the Centre for Science and Culture's abounding examples of the Contrast Principle and Negativity Effect, which coincide with Scarcity Principle claims.

\section{The Contrast Principle and Negativity Effect}

The dissimilarities existing between two objects or ideas are typically perceived to be far more acute when they are presented to audiences in sequence, rather than when they are presented in isolation from one another (Cialdini 2009, 12). As a result, comparisons can be used to persuade individuals to accept certain notions, or buy particular products, far more readily than if no comparisons had been made at all. Contrast persuasion has been shown to operate particularly well in low-to-mid message elaboration likelihood contexts (Pechmann and Esteban 1993). Due to the potential efficacy of contrast persuasion, and the calculated use of unfairly structured comparisons that may include ridicule and biased caricatures of a competitor, direct comparative advertising has occasionally been prohibited and is often legally regulated (James and Hensel 1991).

The Negativity Effect is further subsumed under this code. This effect pertains to the observation that "negative information is often more powerful in creating attitudes (i.e., it is weighted more heavily) than is positive 
information of equal extremity" (Bizer and Petty 2005, 554). Consequently, negative messages assailing concepts or goods tend to result in more potent, comparatively automatic persuasion responses, when compared with positive information communicated to promote ideas or products. In this way, negative information that deliberately opposes an idea acts as a type of peripheral cue towards the contrary position. Accordingly, any comparison made between an advocated product or concept with those supported by a potential competitor are identified as the Contrast Principle, with unfavorable comparisons linked to the Negativity Effect. This can include personal defamatory attacks on the character of an opponent, and the derision of a rival's ideas when compared to those concepts a communicator is attempting to promote.

It is also of note that one routine derogatory motif occurring in select Darwin-skeptic materials is the accusation that evolutionists are fretfully censoring key data that contradicts evolutionary theory. Such allegations are associated with conspiracist narratives that not only criticize opponents, but do so while engendering aspects of a persuasive strategy known as the Scarcity Principle.

\section{The Scarcity Principle}

When an item appears to be in limited supply its scarcity acts as a compelling peripheral shortcut, causing its apparent value and subjective desirability to be greatly increased (Lynn 1991, Lynn and Bogert 1996). In relation to this, when items or ideas become banned or censored, appetites for these commodities and notions are often intensified due to their perceived scarcity. Even the suggestion that information is being suppressed by certain parties augments an audience's desire for that same data, even if people initially disagreed with it (Worchel, Arnold, and Baker 1975). Assertions that a commodity is in short supply, or claims that an idea is being censored are tallied as cases of this persuasive cue in Evolution Wars messages (Aechtner 2014, 194). 


\section{Contrast, Negativity, and the Scarcity Principle in Evolution Wars Media}

Intelligent Design communications possess the highest frequency rates of the Contrast Principle and Negativity Effect exhibited in all Evolution Wars media. The CSC's News and Views is also the lone output to exhibit substantial articulations of the Scarcity Principle. Every occurrence of this latter persuasive cue is affiliated with claims that an evolutionist junta is feverishly censoring data in the desperate attempt to suppress Darwin-skepticism and the wicked societal effects of evolutionary theory (Luskin 2010, Klinghoffer 2009b). All through such conspiracy accusations are value claims centered on the importance of academic freedom, research objectivity, the need for free access to scientific data, the ability to express opinions without fear of institutional censorship, and the rights of citizens to hear all sides in contested science debates. For this reason, such Scarcity Principle statements call to mind numerous convictions that may have culturally cognitive salience for audiences. People with worldviews and personal identities associated with valuing freedom of academic inquiry, and the right of all individuals to question ideas or facts even when they are inconvenient to authorities, may be further influenced by references to these ideals. Moreover, in making censorship claims that Intelligent Design evidence is falling victim to a sinister anti-ID cover-up, CSC writers also protest the injustice of proevolutionist suppression, and call out for fair play (Luskin 2011). In that respect, Scarcity Principle narratives also touch upon the fairness/reciprocity moral foundation as they demand equal treatment in the face of alleged proevolutionist despotism.

In relation to the fairness/reciprocity moral axis, CSC cases of the Contrast Principle and Negativity also feature frequent comparisons of reputed proevolutionist dogmatism and narrow-mindedness. These representations are set against Intelligent Design pleas for academic freedom and the objective pursuit of scientific facts. Such contrast emphasizes that fairness is an attribute typified by ID theorists, with the inverse being true of evolution's supporters (Luskin 2009a). This demarcation further separates censorial 
outgroup evolutionists from freedom pursuing ID-advocates, underscoring in-group/loyalty moral concerns. Aspects of this foundation also seem present in the CSC's comparative onslaughts against proevolutionists such as members of BioLogos and the NCSE, who allege that evolution and religion not need to be in conflict. Within these cases of negative contrast, the in-group status of ID's sound empirical foundations is juxtaposed with what is claimed to be the scientifically and theologically bankrupt positions of all those who attempt to harmonize religion with biological evolution (Egnor 2009b, Luskin 2009b). The former is said to cohere with objective facts and the fundamental tenets of theism, while the latter are described as being scientifically disingenuous and even heretical. What is more, elements of the care/harm moral foundation are also expressed in Center for Science and Culture manifestations of the Contrast Principle and Negativity Effect. This facet of Moral Foundations Theory is formulated in the CSC's negative accounts of evolution's social outcomes, which are viscerally encapsulated in arguments that assert the biological theory has served as a trigger for such evils as Nazism and school shootings (Klinghoffer 2009c, West 2009). According to Intelligent Design theorists, evolutionary theory has and will continue to stimulate iniquity, so to keep people from Darwinian harm it must actively be opposed.

Similar care/harm characteristics are expressed throughout ICR and AiG articulations of the Contrast Principle and Negativity Effect. For example, Institute for Creation Science writers inform audiences that evolution is a satanic tool, which has been used to justify a slew of horrendous evils (Dao 2009, 12). To prevent future societal damage, creationism must be propagated and evolutionary theory resisted. In addition to making similar claims, Answer in Genesis media warn readers that evolution undermines the entire system of the Christianity. Consequently, parents are cautioned to protect their children by not sending them to any religious colleges whose faculty accept evolutionary theory, because this will capsize the faith of the next generation of Christians (Ham 2011a). In sum, such pronouncements help mandate the need to safeguard society overall, and the church more specifically, from evolution's vast and varied detriments. Along with language evoking the care/harm foundation, such discourse in Institute for 
Creation Research media also seems to conjure features of purity/sanctity moral reasoning. ICR's contrast rhetoric calls up the purity/sanctity dyad by branding evolution as a graven image, pronounced to be a substitute god, and a false gospel in Satan's plans to tear down Christian belief (Johnson 2011b, Guliuzza 2011). This fraudulent idol is something that threatens to pollute Christianity with its vile materialistic narratives, while it slanders the sacrosanct Word of God. For the sake of maintaining Christianity's purity, evolution must be expunged from the church.

ICR and AiG allegations also consolidate the boundaries separating Young Earth Creationism from outsider compromise notions, such as theistic evolution and Intelligent Design theory. Throughout such comparisons, in-group/loyalty foundational language demarcates ICR's descriptions of creationism, and its faithfulness to scripture, from all other views related to religiously calamitous accommodationism (Forlow 2011, Morris 2011b). This accomodationism, it is stated, leads directly to apostasy and the erosion of Christian truths. Audiences are implored to remain devoted to God and the Bible, which true Christians value, rather than acceding to the Devil's schemes lying behind the spread of Darwinism (Johnson 2011a). Such entreaties may also be culturally salient for audience members who hold to worldviews in which resisting satanic ploys, as well as staying faithful to God and scripture at all costs, are respected ideals. While making similar claims, Answers in Genesis writers regularly call attention to religious leaders and theological perspectives for their apparent non-creationist theological deficiencies. Unlike these recreant people and ideas, portrayed as forcing human-based distortions upon scripture, Young Earth Creationists are styled as the group most loyal to God and the Bible. Calls are thus put out to Christian publics to join creationists in their steadfast devotion, rather than linking up with non-creationist, anti-biblical, God-denying compromisers (Morris 2009 [1988]).

While contrasting the purportedly God-approved certainty of Young Earth Creationism with all other flawed assumptions, AiG and ICR materials further reinforce authority/respect messages. Echoed claims that the legitimacy of YEC is derived not simply from science, but ultimately from 
God's own 'eyewitness' testimony, besprinkle such contentions and prop up the notion that veneration for God necessitates respecting Young Earth explanations of the world around us (AiG 2010, 85). Accepting anything other than creationism involves undermining God's sovereign word. Amidst such contrast cues, Institute for Creation Research materials also feature a number of Scarcity Principle cases. These involve conspiracist ideation educed in reports about evolutionists suppressing creationist data using propaganda and political scheming. Paralleling similar Intelligent Design claims, these statements also impart fairness/reciprocity moral intuitions by decrying the censorial nature of evolutionists, while pleading for fair treatment (Morris 2011a, Dao 2011). It is through this ambit of charges that creationists orient contrast and scarcity claims around such values as Christian faithfulness, the reliability and authority of the Bible, academic freedom, as well as the need to protect the world from horrendous evils. The latter of these concerns is also expressed in New Atheist Contrast Principle and Negativity Effect cues, which themselves brim with values discourses.

In the case of RDFRS media, the evils mentioned include religiously associated terrorism and the concealment of pedophilia by the Roman Catholic Church (Harris 2010a, b). At the root of such wickedness is a malignant ignorance symptomatic of all religion, which poisons levelheadedness and threatens civil society. Crucially, this ignorance undermines such values as reason, and the truth of science, which must be shielded from the fairytales of belief that diminish human dignity (Aechtner 2016b). What can be identified in these sorts of claims are suggestions of both the care/ harm and in-group/loyalty moral foundations. The prevention of harm is enunciated through reoccurring entreaties to contest the damaging absurdity of religion, with calls to defend human rationality and societies against the bloodshed reaped by blind religious faith (Hitchens 2009). These statements bestride in-group and out-group identifiers, which serve to mark off truly committed atheists from outsiders. Outsiders are not only Darwin-skeptics, but also fellow proevolutionists who are intellectually hampered by religious commitments, as well as individuals who contend that religion and science need not be in conflict (Hitchens 2009). RDFRS media, therefore, delineates 
what views are dangerous to society and incompatible with genuine scientific rationalism. In effect, these assertions also connote purity/sanctity characteristics. In aggregate, rational thought, truth, and science must be kept unpolluted from the cerebral decay and abetted evils that religion elicits. In the end, what can be identified in RDFRS contrast and negativity cues are messages concerning the values of truth and sound thinking, as well as rallying cries to protect them. This includes language intimating many of the same moral intuitions referenced throughout antievolutionist media. Allusions to values and moral frameworks, on the other hand, are not common features of Contrast Principle and Negativity Effect instances isolated in media produced by the NCSE and BioLogos Foundation. For that matter, the so-called accommodationists of the National Center for Science Education and BioLogos are also less likely to wield values discourse when utilizing complex jargon or statistics.

\section{Statistics and Technical Jargon}

\subsection{Statistics}

In his popular text on persuasion, Levine explains, "The inclusion of statistics, even when they're meaningless, can signal expertise" (2003, 33). In relation to this, statistics can persuasively capitalize upon the innumeracy of message recipients. At the same time, "Many people confronted by a marketer's numbers or statistics suspend otherwise natural skepticism in favor of regressive obedience to argument by authority" (Boush, Friestad, and Wright 2009, 71). Statistics, therefore, can act as a marker of expertise, and the inability to fully comprehend the nuances of statistical information frequently leads audiences to peripherally depend upon the credibility of a communicator.

\subsection{Technical Jargon}

Technical jargon includes specialized language that may appear unintelligible to audiences who do not possess the training or expertise required to comprehend it. As with statistics, expert jargon often steers message recipi- 
ents to depend upon a communicator's perceived knowledge and credentials in response to persuasive messages. If appropriately impressive indicators of credibility are present, then such jargon assists in persuasion. Conversely, if specialized language is not accompanied by notable credentials, technical jargon proves to be less convincing. Bearing this in mind, technical parlance can help to elicit persuasion when it is complemented by the peripheral cue Messenger Credibility (Hafer, Reynolds, and Obertynski 1996).

It is also of note that in Evolution Wars media, statistics are frequently used to demonstrate how a significant majority of the population supports either Darwin-skepticism or evolutionary theory. In this way, the use of numerical data coincides with an important facet of the persuasive cue aggregately described here as Social Consensus. This persuasion element includes the subgenres identified as Multiple Sources, Social Proof, and Underdog Effects, which in their own way kindle the idea that an important group of people endorses a marketed product or advertised opinion.

\section{Social Consensus}

\subsection{Multiple Sources}

Hearing the same or similar messages from more than one source has been found to increase message processing in audiences, and it can also serve as a cognitive mental shortcut. This is because "people may use the number of people who support the issue as a simple cue as to the worth of the proposal" (Petty and Cacioppo 1986, 212). Correspondingly, audiences seem more likely to agree with a message stated by several different voices because it appears to reflect popular agreement. Multiple Sources can be classified as the use of three or more sources, all communicating an analogous message within a single communication (Aechtner 2014, 193).

\subsection{Social Proof}

This persuasive cue utilizes an audience's tendency to favor ideas and products that are perceived to be the most dominant or popular (Lun et 
al. 2007). For instance, upon hearing the results of public opinion polls, individuals tend to modify expressed personal opinions to coincide with majority positions (Perse 2001, 115). Hence, a communicator may increase the persuasiveness of a message by indicating that an idea or product is readily accepted by a large number of people. Such appeals to social majorities can generate long-lasting opinions and serve as peripheral cues, especially when individuals are unfamiliar with information and unsure about how to act (Sechrist and Stangor 2007).

\subsection{Underdog Effects}

An underdog can be described as an individual, group, or premise that is expected to lose a contest due to a lack of ability, insufficient popularity, or being the victim of injustice. This persuasion tactic involves rallying an audience to enlist with a seemingly noble minority consensus that is fighting against the odds. Underdog Effects are often less predictable than Social Proof cues, though they can still prove to be influential. For instance, during political elections voter turnouts are often appreciably higher among supporters of less popular, underdog candidates (Levine and Palfrey 2007). Furthermore, biographical underdog stories, described as the marketing of disadvantage, have proven effective in fostering consumer purchasing and brand loyalty (Paharia et al. 2011). Underdog effects appear most effective in low elaboration likelihood contexts, either due to an audience's lack of information or disinterest in a message's topic (Fleitas 1971).

\section{Statistics and Consensus Cues}

Darwin-skeptics frequently oppose the notion of common biological descent by insisting that there exists a chasm of substantive traits which separate humans from animals (Aechtner 2016b, 500-501). These characteristics, which include but are not limited to human consciousness, the capacity for reason, and moral proclivities, are said to confirm human exceptionalism while being unexplainable by means of natural selection. Correspondently, it 
is asserted that there exist two principal and apparently contradictory views of humankind. The first involves recognizing humanity's God-established distinctiveness and the intrinsic value of all people, epitomized by the notion of Imago Dei. In the second view, however, our evolutionary animal ancestry is embraced, resulting in the diminution of human specialness as well as the erosion of morality and religiously sustained values. Modern antievolutionists utilize statistics to further the argument; presenting mathematical information that seemingly reveals the immense genetic differences between humans and other fauna (Richards 2010, Tomkins 2009, 2011). Conspicuously then, Statistics and Technical Jargon cues in ICR, Answers in Genesis, and CSC media intersect with discussions of human nature, morality, and the preservation of religious values. Hence, numerical data attempting to refute the similarities between human and chimpanzee genomes, for example, may be particularly striking for audiences with culturally cognitive commitments to an ontological human-animal divide. Moreover, such statistics may resonate with audiences whose religious and cultural identities are paired with the thesis that human rights and dignity are based upon the assumption that all people bear a divine image.

Along with employing statistics when considering human nature and values, Darwin-skeptic media also apply stats to advertise the numbers of people who maintain similar group commitments to those upheld by Darwin-skeptics. Opinion poll results, for instance, are said to verify that an important majority of non-elite individuals reject evolutionary theory or accept that the Bible is inspired by God. Survey data are also employed to demonstrate how large numbers of citizens also support 'fairness' in school curricula through the teaching of alternative, non-Darwinist viewpoints (Luskin 2009c). Tied up with such numerical information are messages indicative of certain moral foundations. Hence, Answers in Genesis writers use survey results to stress the evidently deplorable state of Evangelical Christianity, which is experiencing an exodus of young Christians who are turning their backs on the church and biblically founded moral values (Farris 2011). These statistics are then used to bolster what might be considered purity/sanctity and authority/respect formulations. Namely, it is stated that 
the theological integrity of Evangelicalism, biblical morals, as well as the size of church communities, will all be restored when congregations reembrace an undiluted respect for scripture represented in Young Earth Creationist hermeneutics and faithfulness. The use of poll data across Intelligent Design media also features rudiments of the fairness/reciprocity moral axis. CSC representatives broach the subject of fairness within articles contending that survey numbers reveal how evolution maintains only modest public support (Luskin 2011). Surely then, it is unjust for a marginal group of elites to push evolutionary theory upon the majority of citizens, as the theory's supporters labor to restrict both antievolutionist information and the personal autonomy of individuals.

In appealing to surveys and statistical majorities, these claims coincide with Social Consensus cues, as they detail how a multitude of people share Darwin-skeptic convictions. Values discourses and moral foundations are further advanced through affiliated Social Proof narratives and underdog declarations. This occurs in ICR's descriptions of creationists as gallant resisters of a proevolutionist hegemony, struggling in an increasingly secular and Christian-hating world. Amidst such statements are invocations for Christians to venerate the true authority of God and his Word over the counterfeit influences exerted by non-creationist academics and policy makers (Thomas 2011, 17). These petitions seem to suggest authority/ respect principles as they establish for audiences the genuine powers that Christians should be expressing deference to. At the same time, cases of Social Proof and Underdog Effects in Answers in Genesis and ICR media reaffirm how crowds of people around the globe, including an underdog contingent of Darwin-skeptic scientists, maintain the group commitments shared by Evangelical audience members. Such Social Consensus cues do not simply mention that there are significant populations who endorse creationism, but they also iterate specific Christian values that these publics apparently adhere to. Through this, Social Proof cues and underdog claims reference more than just numbers of people, but also several conservative Evangelical ideals. Such Christian Evangelical values as respecting the Bible as the conclusive source of knowledge about the world and how it came to 
be, and the importance of honoring scripture as the sole authority on how people should conduct themselves in their daily lives, are often mentioned. In this fashion, antievolutionist delivery of Social Consensus cues differs from those appearing in NCSE articles.

National Center for Science Education media are the only counter-creationist communications to exhibit Social Consensus cues to any considerable degree. However, in NCSE materials appeals to popular agreement are not marked by the types of overt values statements found in antievolutionist materials. The same observation holds true when comparing Darwin-skeptic instances of Statistics and Technical Jargon with those appearing in BioLogos and NCSE media. Though both antievolutionist and proevolutionist media feature this persuasive element, Darwin-skeptic pundits recurrently yoke culturally cognitive values and language suggestive of moral foundations to statistics in ways not exhibited in the latter two organisations' broadcasts. It is in recognizing these distinctions that a fuller picture of Evolution Wars persuasion emerges. An image that includes not merely tallies of persuasion elements, but one in which the dimensionality of cultural values and moral intuitions in Darwin-skeptic and proevolutionist media are also taken into consideration.

\section{Conclusion: Conflict, Values, and Evolution Wars Persuasion}

In view of the preceding analysis, it is possible to reassess mass persuasion and persuasive cue occurrence rates in Evolution Wars media. Though counter-creationist media exhibit fewer cues overall when compared to Darwin-skeptic communications, it is still the case that several of the same persuasion elements are present in all Evolution Wars media. In fact, for certain suasion characteristics proevolutionist articles demonstrate higher occurrence rates than do even some Darwin-skeptic outputs. Accordingly, NCSE and BioLogos articles are more likely to showcase Source Cues as well as Statistics and Technical Jargon than the CSC's Intelligent Design advocating media. The NCSE's proevolutionist materials also exhibit greater incident rates of Social Consensus than do either Answers in Genesis or 
CSC antievolutionist messages. Moreover, New Atheist authors employ Rhetorical Questions to a degree unmatched by any other Evolution Wars media maker. Nonetheless, further insights into Evolution Wars persuasion efforts can be gained when bearing in mind the co-occurrence of values discourses and language denotative of moral foundations.

A fundamental observation derived from this paper's survey is that Darwin-skeptic media not only display a greater array of persuasion cues than do counter-creationist materials, but they do so while frequently referring to shared values and defining group commitments. Along with culturally cognitive values discourses, Darwin-skeptic communications also include messages resonating with the five morally foundational axes of care/harm, fairness/reciprocity, in-group/loyalty, authority/respect, and purity/sanctity. As a result, persuasive heuristics in Young Earth Creationist and Intelligent Design supporting materials are interlinked with values claims associated with Evangelical Christianity, or theism more generally, as well as moral ideals and notions of freedom and personal autonomy. By way of contrast, the proevolutionist broadcasts circulated by the National Center for Science Education and BioLogos display a comparative lack of references to shared values, cultural commitments, or suggestions of moral intuitions in relation to the very same persuasive cues. Consequently, even though NCSE articles may present greater occurrence rates of such elements as Source Cues, Statistics and Technical Jargon, or Social Consensus than does the CSC's antievolutionist rhetoric, Intelligent Design media are disposed to mentioning culturally cognitive values and using morally foundational language when employing the selfsame persuasion attributes. There is, therefore, an additional mechanism of influence at play in Answers in Genesis, Institute for Creation Research, and Center for Science and Culture media that is largely out of the frame in NCSE and BioLogos communications. Namely, this is the influence of validating audiences' worldviews, reinforcing cultural identities, affirming group beliefs, and conveying language referential of moral axes while expressing persuasive cues.

Furthermore, publications authored by New Atheists resemble Darwin-skeptic materials more closely than other proevolutionist media in 
terms of values discourses and statements suggestive of moral foundations. RDFRS articles display the least variety of persuasive cues exhibited by any Evolution Wars cohort, yet when New Atheist's leaders express Asking Questions or the Contrast Principle and Negativity effect, they do so while using value-laden language. To be sure, the values and mores mentioned differ by and large from those broached by their Darwin-skeptic rivals. These include remarks about the inviolability of rational thought, or the unethical practices of religious institutions, and the violence religions are said to cause. Despite divergent value themes, however, similarities exist in the fact that both Darwin-skeptics and fervent atheists frequently articulate values claims in combination with persuasive cues. Also, in a similar manner to that of antievolutionists, New Atheist communications express persuasive characteristics in concert with statements signaling moral foundations. Though New Atheist materials only allude to properties of in-group/loyalty and purity/sanctity, while Darwin-skeptic spokespeople suggest all five foundations, these references still make RDFRS articles unique among the proevolutionists.

An additional commonality that links antievolutionist media with New Atheist articles are assertions that religion is incongruous with evolutionary theory. While delivering persuasive cues and values discourses, Young Earth Creationists, Intelligent Design theorists and New Atheists together assert that religion and evolution are irreconcilable. For the Darwin-skeptics the incompatibilities are said to come from evolution's contradiction of scripture, its materialist ontology, and the ways in which evolution provokes great evils. In the case of New Atheists, the hard truths of science undergirding evolution controvert the superstitious worldviews of religion and their sacred texts. Along the same lines, spokespeople from all three camps are quick to call out the accommodationists who would say otherwise; contending, as do NCSE and BioLogos members, that evolution and religion need not be adversaries. Consequently, what can be discerned in Evolution Wars mass communications is that media makers representing conflict positions on evolution and religion are also those who readily field culturally cognitive values and morally foundational language in tandem with persuasion cues. 
On the other hand, representatives who might be deemed 'moderates' in the Evolution Wars use a handful of persuasive cues while advancing religion-evolution concord, but they do so largely without values parlance. Therefore, while media from all of the Evolution Wars groups analyzed here feature persuasive heuristics, it is the case that values claims and morally charged language are concentrated specifically within the works of those who advocate conflict.

A corollary is that combative Evolution Wars messages, produced by Darwin-skeptics and New Atheist leaders, incorporate additional persuasion dynamics not readily perceptible in NCSE or BioLogos media. This includes culturally cognitive prompts and morally foundational markers that could add to the persuasive salience of conflict-oriented media for targeted audiences. Accordingly, messages relating to religion-evolution conflict seem to be tapping into another level of influence that is potentially making them more persuasively enduring. In this way, conflict-themed media could be shaping Evolution Wars persuasion more decisively than non-Darwin-skeptic and non-New Atheist voices, which lack substantial references to values and moral concerns.

\section{Bibliography}

Aechtner, Thomas. 2014. "Darwin-Skeptic Mass Media: Examining Persuasion in the Evolution Wars." Journal of Media and Religion 13 (4): 187-207. doi: 10.1080/15348423.2014.971559.

Aechtner, Thomas. 2016a. "Challenging the Darwin Skeptics: Examining Proevolutionist Media Persuasion.” Journal of Media and Religion 15 (2):78-99. doi: 10.1080/15348423.2016.1177346.

Aechtner, Thomas. 2016b. "Terrorism in the Evolution Wars: Mass Media and Human Nature.” Theology and Science 14 (4): 495-517. doi: 10.1080/14746700.2016.1231983.

Ahluwalia, Rohini, and Robert E. Burnkrant. 2004. "Answering Questions about Questions: A Persuasion Knowledge Perspective for Understanding the Effects of Rhetorical Questions." The Journal of Consumer Research 31 (1): 26-42.

AiG. 2010. "10 Basics Every Creationist Must Know." Answers 5 (2): 85. 
Allport, Floyd H., and Milton Lepkin. 1945. "Wartime Rumors of Waste and Special Privilege: Why Some People Believe Them.” The Journal of Abnormal and Social Psychology 40 (1): 3-36. doi: 10.1037/h0058110.

Anastasio, Phyllis A., Karen C. Rose, and Judith Chapman. 1999. "Can the Media Create Public Opinion? A Social-Identity Approach.” Current Directions in Psychological Science 8 (5): 152-155.

Bauchman, Voddie, Jr. 2009. “Life’s Toughest Questions.” Answers 4 (2): 58-65.

Bizer, George Y., and Richard E. Petty. 2005. "How We Conceptualize Our Attitudes Matters: The Effects of Valence Framing on the Resistance of Political Attitudes.” Political Psychology 26 (4): 553-568.

Boush, David M., Marian Friestad, and Peter Wright. 2009. Deception in the Marketplace: The Psychology of Deceptive Persuasion and Consumer Self Protection. New York: Routledge.

Burger, Jerry M., Nicole Messian, Shebani Patel, Alicia del Prado, and Carmen Anderson. 2004. "What a Coincidence! The Effects of Incidental Similarity on Compliance.” Personality and Social Psychology Bulletin 30 (1): 35-43.

Cartwright, Dorwin. 1949. "Some Principles of Mass Persuasion: Selected Findings of Research on the Sale of United States War Bonds." Human Relations 2 (3): 253-267. Cialdini, Robert B. 2009. Influence: Science and Practice. 5th ed. Boston: Pearson Education.

Coyne, Jerry. 2009. “Must We Always Cater to the Faithful When Teaching Science?” Why Evolution is True, 24 March.

https://whyevolutionistrue.wordpress.com/2009/03/24/must-we-always-cater-tothe-faithful-when-teaching-science/.

Dao, Christine. 2009. "Charles Darwin: The Man Behind the Monkey.” Acts\&Facts 38 (2): 12.

Dao, Christine. 2011. “Texas Schools Seek Science Supplements.” Acts\&Facts 40 (2): 19 .

Dawkins, Richard. 2010. “The Pope Should Stand Trial.” Richard Dawkins Foundation for Reason and Science, accessed February 11. https://richarddawkins. net/2010/04/the-pope-should-stand-trial/.

Day, Martin V., Susan T. Fiske, Emily L. Downing, and Thomas E. Trail. 2014. "Shifting Liberal and Conservative Attitudes Using Moral Foundations Theory.” Personality and Social Psychology Bulletin 40 (12): 1559-1573. doi: 10.1177/0146167214551152.

Egnor, Michael. 2009a. “Dr. Jeffery Shallit on Eugenic Morality: "Why, exactly, would the world be better off with more Down's syndrome children?”.” Center 
for Science and Culture, accessed October 14. http://www.evolutionnews. org/2009/05/dr_jeffery_shallit_why_is_euge020261.html.

Egnor, Michael. 2009b. “Ontology Recapitulates Philology.” Center for Science and Culture, accessed October 25. http://www.evolutionnews.org/2009/08/ ontology_recapitulates_philolo023851.html.

Egnor, Michael. 2009c. "Why Is Censorship of Scrutiny so Much a Part of Evolutionary Science?”. Center for Science and Culture, accessed October 25. http://www. evolutionnews.org/2009/04/why_is_censorship_of_scrutiny019511.html.

Farris, Michael. 2011. “Showing Children the Way.” Answers 6 (4): 78.

Fleitas, Daniel W. 1971. "Bandwagon and Underdog Effects in Minimal-Information Elections.” The American Political Science Review 65 (2): 434-438.

Ford, Lawrence E. 2010a. “Celebrating with Gusto and Gratitude.” Acts\&Facts 39 (7): 3. Ford, Lawrence E. 2010b. “Stand Up! Stand Up for Jesus!” Acts\&Facts 39 (12): 3.

Forlow, Brad. 2011. “Genesis Under the Microscope.” Acts\&Facts 40 (10): 4-5.

Guliuzza, Randy J. 2011. “Darwin's Sacred Imposter: Natural Selection’s Idolatrous Trap." Acts\&Facts 40 (11): 12-15.

Hafer, Carolyn L., Kelly L. Reynolds, and Monika A. Obertynski. 1996. "Message Comprehensibility and Persuasion: Effects of Complex Language in Counterattitudinal Appeals to Laypeople.” Social Cognition 14 (4): 317-337.

Haidt, Jonathan, and Jesse Graham. 2007. "When Morality Opposes Justice: Conservatives Have Moral Intuitions that Liberals may not Recognize." Social Justice Research 20 (1): 98-116. doi: 10.1007/s11211-007-0034-z.

Ham, Ken. 2011a. “Counterfeit Christian College.” Answers 6 (3): 54-57.

Ham, Steve. 2011b. “Unity ... At What Cost?” Answers 6 (3): 58-61.

Harris, Sam. 2009. “The Strange Case of Francis Collins.” The Blog: Sam Harris, August 6. http://www.samharris.org/blog/item/the-strange-case-of-francis-collins.

Harris, Sam. 2010a. “Bringing the Vatican to Justice.” The Huffington Post, accessed February 19. http://www.huffingtonpost.com/sam-harris/bringing-the-vatican-toj_b_571088.html?ir=Australia.

Harris, Sam. 2010b. "What Obama Got Wrong About the Mosque.” The Daily Beast, accessed 19 February. http://www.thedailybeast.com/articles/2010/08/13/ ground-zero-mosque.html.

Hitchens, Christopher. 2009. “Assassins of the Mind.” Vanity Fair, accessed February 12. https://www.vanityfair.com/news/2009/02/hitchens200902.

Hodge, Bodie. 2011. “Global Flood.” Answers 6 (3): 156.

James, Karen E., and Paul J. Hensel. 1991. "Negative Advertising: The Malicious Strain of Comparative Advertising." Journal of Advertising 20 (2): 53-69. 
Johnson, James J. S. 2010. “Tackling Charges of Biblical Inconsistency: Putting the Pieces Together to Form the Big Picture.” Acts\&Facts 39 (7): 8-9.

Johnson, James J. S. 2011a. “Culpable Passivity: The Failure of Going with the Flow.” Acts\&Facts 40 (7): 8-10.

Johnson, James J. S. 2011b. “Human Suffering: Why This Isn’t the ‘Best of All Possible Worlds'.” Acts\&Facts 40 (11): 8-10.

Kahan, Dan. 2012. "Cultural Cognition as a Conception of the Cultural Theory of Risk.” In Handbook of Risk Theory: Epistemology, Decision Theory, Ethics, and Social Implications of Risk, edited by Sabine Roeser, Rafaela Hillerbrand, Per Sandin and Martin Peterson, 725-759. Dordrecht: Springer.

Kahan, Dan, and Donald Braman. 2008. "The Self-Defensive Cognition of Self-Defense.” The American Criminal Law Review 45 (1): 1-65.

Kahan, Dan, Donald Braman, Geoffrey Cohen, John Gastil, and Paul Slovic. 2010. “Who Fears the HPV Vaccine, Who Doesn't, and Why?: An Experimental Study of the Mechanisms of Cultural Cognition." Law and Human Behavior 34 (6): 501-516. doi: 10.1007/s10979-009-9201-0.

Kahan, Dan, Hank Jenkins-Smith, Tor Tarantola, Carol Silva, and Donald Braman. 2015. "Geoengineering and Climate Change Polarization." The ANNALS of the American Academy of Political and Social Science 658 (1): 192-222. doi: 10.1177/0002716214559002.

Kahan, Dan, Hank Jenkins-Smith, and Donald Braman. 2011. “Cultural Cognition of Scientific Consensus.” Journal of Risk Research 14 (2): 147-174. doi: 10.1080/13669877.2010.511246.

Karmarkar, Uma R., and Zakary L. Tormala. 2010. “Believe Me, I Have No Idea What I'm Talking About: The Effects of Source Certainty on Consumer Involvement and Persuasion.” The Journal of Consumer Research 36 (6): 1033-1049.

Klinghoffer, David. 2009a. “At Bloggingheads, Fleeing the Ritual Contamination of 'Creationism'.” Center for Science and Culture, accessed October 20.

http://www.evolutionnews.org/2009/09/the_contamination_of_creationi024741.html. Klinghoffer, David. 2009b. "Robert Wright's Bloggingheads.tv Censors Intelligent Design Interview.” Center for Science and Culture, accessed October 20. http:// www.evolutionnews.org/2009/08/robert_wrights_bloggingheadstv024581.html. Klinghoffer, David. 2009c. “The Strange Case of Little Green Footballs II.” Center for Science and Culture, accessed October 20. http://www.evolutionnews. org/2009/02/the_strange_case_of_little_gre_1016671.html.

Landis, Don. 2011. “2. Claims of Divine Authorship.” Answers 6 (2): 56-57.

Lanham, Richard A. 1991. A Handlist of Rhetorical Terms. 2nd ed. London: University of California Press. 
Lawton, Graham. 2010. “Templeton Prizewinner: We Need science plus Morality.” New Scientist, accessed April 10. http://www.newscientist.com/article/ mg20627546.800-templeton-prizewinner-we-need-science-plus-morality.html.

Levine, David K., and Thomas R. Palfrey. 2007. “The Paradox of Voter Participation? A Laboratory Study.” The American Political Science Review 101 (1): 143-158.

Levine, Robert. 2003. The Power of Persuasion: How We're Bought and Sold. New Jersey: John Wiley \& Sons.

Lun, Janetta, Stacey Sinclair, Erin R. Whitchurch, and Catherine Glenn. 2007. “(Why) Do I Think What You Think? Epistemic Social Tuning and Implicit Prejudice.” Journal of Personality and Social Psychology 93 (6): 957-972.

Luskin, Casey. 2009a. "Barbara Forrest Exposes Her Intolerance, Misrepresents Darwin-Doubting Scientist.” Center for Science and Culture, accessed October 19. http://www.evolutionnews.org/2009/10/barbara_forrest_exposes_her_int026261. html.

Luskin, Casey. 2009b. "Eugenie Scott Claims Evolution Is Threatening to Certain Christian Traditions.” Center for Science and Culture, accessed October 19. http:// www.evolutionnews.org/2009/06/eugenie_scott_claims_evolution022041.html.

Luskin, Casey. 2009c. "A Partisan Affair (Part 6): False Claims about Science Education Policy in Edward Humes' Pseudo-History of Kitzmiller, 'Monkey Girl'.” Center for Science and Culture, accessed October 19.

http://www.evolutionnews.org/2009/01/a_partisan_affair_part_6_false015161.html. Luskin, Casey. 2010. “Documents Reveal Intolerance Towards Intelligent Design at the California Science Center." Center for Science and Culture, accessed October 19. http://www.evolutionnews.org/2010/08/documents_reveal_intolerance_t037441.html.

Luskin, Casey. 2011. “How the Science Teachers' Lobby Keeps Its Constituents in the Dark on Evolution." Center for Science and Culture, accessed January 25. http:// www.evolutionnews.org/2011/03/how_the_science_teachers_lobby044471.html. Lynn, Michael. 1991. "Scarcity Effects on Value: A Quantitative Review of the Commodity Theory Literature.” Psychology \& Marketing 8 (1): 43-57.

Lynn, Michael, and Paulette Bogert. 1996. “The Effect of Scarcity on Anticipated Price Appreciation.” 1978-1984 26 (22).

Matthews, Mike. 2010. “The Humility Factor: Understanding God's Truth.” Answers 5 (1): 82.

Menton, David. 2010. “Uniqueness of Man.” Answers 5 (2): 54-55.

Morris, Henry M. 2009 [1988]. "Dangerous Turn Ahead: Traveling Down the Road to Compromise.” Acts\&Facts 38 (6): 4. 
Morris, Henry M. 2011 [1995]. “Global Flood, Global Impact: The Legacy of The Genesis Flood.” Acts\&Facts 40 (2): 10-11.

Morris, John D. 2011a. “The Creation Movement's Firm Foundation.” Acts\&Facts $40(2): 8-9$.

Morris, John D. 2011b. “Doubt Versus Unbelief.” Acts\&Facts 40 (8): 15.

Mortenson, Terry. 2010. “Six Literal Days.” Answers 5 (2): 50.

Paharia, Neeru, Anat Keinan, Jill Avery, and Juliet B. Schor. 2011. “The Underdog Effect: The Marketing of Disadvantage and Determination through Brand Biography." Journal of Consumer Research 37 (5): 775-790.

Pechmann, Cornelia, and Gabriel Esteban. 1993. “Persuasion Processes Associated with Direct Comparative and Noncomparative Advertising and Implications for Advertising Effectiveness.” Journal of Consumer Psychology 2 (4): 403-432.

Perse, Elizabeth M. 2001. Media Effects and Society. Mahwah: Lawrence Erlbaum Associates.

Petty, Richard E., and John T. Cacioppo. 1984. “The Effects of Involvement on Responses to Argument Quantity and Quality: Central and Peripheral Routes to Persuasion.” Journal of Personality and Social Psychology 46 (1): 69-81.

Petty, Richard E., and John T. Cacioppo. 1986. Communication and Persuasion: Central and Peripheral Routes to Attitude Change. New York: Springer-Verlag.

Priester, Joseph R., and Richard E. Petty. 2003. “The Influence of Spokesperson Trustworthiness on Message Elaboration, Attitude Strength, and Advertising Effectiveness.” Journal of Consumer Psychology 13 (4): 408-421.

Richards, Jay W. 2010. “Are Chimps and Humans Really All That Much Alike?”. Center for Science and Culture, accessed October 14. http://www.evolutionnews. org/2010/02/are_chimps_and_humans_really_a031631.html.

Sechrist, Gretchen B., and Charles Stangor. 2007. "When are Intergroup Attitudes Based on Perceived Consensus Information?: The Role of Group Familiarity.” Social Influence 2 (3): 211-235.

Shumann, David W., Richard E. Petty, and D. Scott Clemons. 1990. "Predicting the Effectiveness of Different Strategies of Advertising Variation: A Test of the Repetition-Variation Hypotheses.” The Journal of Consumer Research 17 (2): 192-202.

Smith, Anika. 2011. “Playing “Science Says” Is a Political Game.” Center for Science and Culture, accessed January 25. http://www.evolutionnews.org/2011/01/ playing_science_says_is_a_poli042541.html.

Snelling, Andrew A. 2009. “Genesis: Real, Reliable, Historical.” Acts\&Facts 38 (9): 12-14. 
Stiff, James B., and Paul A. Mongeau. 2003. Persuasive Communication. 2nd ed. New York: Guilford Press.

Thomas, Brian. 2011. “The Stones Cry Out: What Rocks and Fossils Say about the Age of the Earth.” Acts\&Facts 40 (1): 17.

Tomkins, Jeffrey. 2009. "Human-Chimp Similarities: Common Ancestry or Flawed Research?” Acts\&Facts 38 (6): 12-13.

Tomkins, Jeffrey. 2011. "First Phase Complete in Human and Chimp Genome-Wide DNA Comparison.” Acts\&Facts 40 (12).

Upchurch, John. 2011. “The Danger of BioLogos: Blurring the Line Between Creation and Evolution.” Answers 6 (4): 38-41.

West, John G. 2009. “Slouching Toward Columbine: Darwin's Tree of Death.” Center for Science and Culture, accessed October 18. http://www.evolutionnews. org/2009/04/slouching_toward_columbine_dar019691.html.

Wheeler, Christian S., Richard E. Petty, and George Y. Bizer. 2005. "Self-Schema Matching and Attitude Change: Situational and Dispositional Determinants of Message Elaboration." Journal of Consumer Research 31 (4): 787. doi: $10.1086 / 426613$.

Wolsko, Christopher, Hector Ariceaga, and Jesse Seiden. 2016. "Red, White, and Blue Enough to be Green: Effects of Moral Framing on Climate Change Attitudes and Conservation Behaviors.” Journal of Experimental Social Psychology 65: 7-19. doi: 10.1016/j.jesp.2016.02.005.

Worchel, Stephen, Susan Arnold, and Michael Baker. 1975. “The Effects of Censorship and Attractiveness of the Censor on Attitude Change." Journal of Applied Social Psychology 5 (3): 227-239. 